\title{
LA FAMILIA CORELLA. 1457, UN CASO DE BANDOLERISMO NOBILIARIO
}

\author{
Manuel Benítez Bolorinos \\ UnIVERSIDAD DE ALICANTE
}

\begin{abstract}
Resumen: En junio de 1457, los batles y oficiales de Aspe, Elda, Petrer y Salinas, tierras pertenecientes al Conde de Cocentaina, atacaron la huerta de Crevillente con veinticinco hombres a caballos y quinientos a pie. El resultado fue la captura de seis moros, ganado y ropas valoradas en quinientos florines, matando a un moro e hiriendo a otro. Como consecuencia, las autoridades de Elche que, como Crevillente, pertenecían a la ciudad de Barcelona, protestaron ante este hecho. El suceso era un acto de bandolería nobiliaria que causó a su vez un conflicto jurisdiccional entre dos señores feudales distintos, con la intervención final de Juan II de Navarra, lloctinent general del Reino de Valencia.
\end{abstract}

Palabras clave: Aspe, bandolería, Barcelona, Conde de Coentaina, Elche, mudéjar, Vinalopó.

Abstract: In June 1457, the batles and officers from Aspe, Elda, Petrer and Salinas, lands belonging to the Count of Cocentaina, attacked the fertile region of Crevillente; they counted on twenty-five men on horseback and five hundred men on foot. The result was the capture of six moors, cattle and clothes to the value of five hundred florians, wich included a moor who and another of them who was wounded. Consequently, the authorities of Elche, like Crevillente, belonged to the city of Barcelona, complained about it. Obviously, such a raid was an act of banditry from part of the nobility that caused a jurisdictional conflict between two different feudal domains and the final intervention of Juan II of Navarra (lloctinent general of the Kingdom of Valencia).

Keywords: Aspe, banditry, Barcelona, Count of Cocentaina, Elche, moor, Vinalopó.

Los actos de violencia en las poblaciones que se extienden a lo largo del río Vinalopó durante la baja Edad Media pueden circunscribirse a varios ámbi- 
tos: conflictos entre señores feudales, violencia entre representantes de distintas comunidades religiosas, enfrentamientos bélicos entre las coronas de Castilla y Aragón, o incursiones granadinas en territorio cristiano con resultado de saqueo, destrucción y secuestro. La suma de estos acontecimientos no derivaba normalmente en una violencia cotidiana, sino en una serie de «accidentes» que salpicaban las relaciones diarias y condicionan tanto la visión como las relaciones con el otro, presente en el mismo territorio hasta la definitiva expulsión de los moriscos.

Entre estos actos de violencia destacan las correrías promovidas o apoyadas por los señores feudales asentados en el sur de Reino de Valencia, bandolerías que en muchas ocasiones se iniciaban para lograr un mayor control sobre el territorio y sus habitantes. Dentro de este grupo de acciones armadas nos encontramos con un documento muy esclarecedor procedente del Archivo del Reino de Valencia.

Fechado el 9 de septiembre de 1457, describe las relaciones existentes en torno al Vinalopó entre la monarquía aragonesa, el conde de Cocentaina, la ciudad de Elche, los pobladores musulmanes y los cristianos.

Teniendo como punto de partida una correría de asalto, saqueo y rapto, podemos atisbar un conflicto entre señores feudales que derivó en otro de competencias jurisdiccionales que afectó a las poblaciones de Elda, Aspe, Petrer, Salinas, Elche y Crevillente. Estos acontecimientos se sitúan dentro de un marco de rivalidad señorial, de la que se desprenden diversos conflictos.

\section{CONTEXTO SEÑORIAL}

En el año 1420, doña Violante de Bar había vendido los alodios de Aspe y Elda a Alfonso Ximén Pérez de Corella, copero mayor del rey Alfonso V de Aragón. Desde entonces, la familia Corella dirigió los destinos de estas y otras poblaciones de la comarca durante cerca de setenta años. ${ }^{1}$ Además, en 1448 Ximén Pérez de Corella fue nombrado conde de Cocentaina por los servicios prestados al rey Alfonso $\mathrm{V}$ en la conquista de Nápoles, con lo que el linaje de los Corella alcanzó un status muy significativo ${ }^{2}$.

\footnotetext{
1. En 1386, el rey Juan I entregó Elda, Novelda, Aspe, La Mola y otras poblaciones a la reina Violante. Ésta vendió en 1420 los castillos y lugares de Elda y Aspe por 23.650 libras a Ximèn Pérez de Corella, caballero y copero del rey, y a Francesc d'Arinyó, secretario del mismo rey. [Ferrer i Mallol, M. T., Les aljames sarraïnes de la governació d'Oriola en el segle XIV. CSIC, Barcelona, 1988, p. 43.]

2. La familia Corella mantuvo estas poblaciones hasta que en el año 1497, Juan Ruiz de Corella vendió el lugar de Aspe a Gutierre de Cárdenas, que en aquel momento ya era señor de Elche, con lo cual, algunos de los conflictos en el medio Vinalopó se diluyeron, aunque no desaparecieron del todo. [VV.AA. Aspe, medio físico y aspectos humanos, Ayuntamiento de Aspe, 1988, p.194]
} 
De este modo, dos familias coincidieron en el medio Vianlopó durante la mayor parte del siglo xv, los Corella y los Maça de Liçana ${ }^{3}$. La confrontación entre ambos linajes por lograr una mayor influencia política ante el rey de Aragón llevó a periodos de enfrentamiento, con acciones tendentes a la destrucción de cosechas y a la captura de mudéjares pertenecientes al otro señor ${ }^{4}$.

Sin embargo, el relato de lo acontecido en el año 1457, no nos habla de un conflicto directo entre los Corella y los Maça de Liçana, sino de una correría por la huerta de Crevillente, propiedad, como Elche, de la ciudad de Barcelona 5 .

\section{EL RELATO DE LOS ACONTECIMIENTOS}

Según indica el documento, la bandolería tuvo lugar a comienzos del verano del año $1457 .{ }^{6} \mathrm{El}$ texto acusa directamente a los batles y oficiales de Elda, Aspe, Petrer y Salinas, vasallos del conde de Cocentaina, don Ximén Pérez de Corella. Estos batles dirigieron a veinticinco hombres a caballo y quinientos a pie -lo cual parece una cifra relevante para este tipo de acciones-, y entraron a saco en la huerta crevillentina. Lo hicieron «ma armada, banderes, steses, trompetes sonants...», dando paso a una acción en la que estuvieron «corrent, tallant, robant, matant e naffrant, tirant ballestas enerbades, aço a aplegar a les parets del dit loch»?.

El resultado fue la captura de seis moros, ganado y ropas valoradas en más de quinientos florines, matando a un moro e hiriendo a otro. ${ }^{8}$ Los seis capturados, junto con el resto del botín, fueron trasladados hasta la localidad de Aspe. ${ }^{9}$

3. Señores estos últimos de Novelda y Monóvar. Los Maça de Liçana adquirieron el señorío de Novelda en diciembre de 1392. [Ferrer i Mallol, M. T. Les aljames sarraïnes..., p.43]

4. Dentro de este grupo de acontecimientos bélicos destaca la «batalla sangrante» de 1463, que tuvo lugar en los llanos de Aspe, o los saqueos en el marquesado de Villena y en el valle de Elda, con la captura de 32 moras y 4 moros en Novelda, o varios asaltos producidos en Monforte del Cid. GonzÁlez i Hernández, M. À., Musulmans, jueus i cristians a les terres del Vinalopó (1404-1594), Centre d'Estudis Locals del Vinalopó, Petrer, 2002, pp. 42-43.

5. Crevillete y Elche fueron la garantía del préstamo de 50.000 florines otorgados al infante Martín para pagar una expedición a la isla de Sicilia en 1392. [Ferrer i MALlol, M. T., «L'alfaquí Mahomat Alhaig i la lluita pel poder a la moreria d'Elx (1448-1457)». Los mudéjares valencianos y peninsulares. Revista d'Historia Medieval. Valencia. $\mathrm{N}^{\circ} 12,2001-2002$, p. 186.] Elche perteneció al señorío de Barcelona hasta 1460. Posteriormente pasó a ser territorio de realengo (1461-1470), quedando a continuación bajo el señorío de la familia Cárdenas. [GonzÁlez i Hernández, M. À., Musulmans..., p.44]

6. La fecha dada en el documento es «dos mesos e mig poch mes o menys» antes de la elaboración del presente documento, por lo que podemos hablar de finales de junio para el asalto.

7. ARV, Real, 279, fol. 209v.

8. En los primeros años de la dominación aragonesa, la población cristiana se concentraba en el litoral, mientras que en el Vinalopó la población era mayoritariamente mudéjar, aunque también había población sarracena en el litoral y aljamas en la huerta de Elche. [Ferrer i Mallol, M. T., Les aljames sarrä̈nes..., p.5]

9. ARV, Real, 279, fol. 209v. 
Nos encontramos ante un acto de violencia cometido presumiblemente por un grupo de musulmanes, al frente de los cuales se encuentran los oficiales cristianos del conde de Cocentaina ${ }^{10}$. Las victimas de asalto son, al mismo tiempo, mudéjares que pertenecen a otro señorío. No se trata, en este caso, de una muestra de violencia promovida por los integrantes de una comunidad religiosa contra integrantes de otra comunidad para obtener el pago de un rescate o como consecuencia de una represalia motivada por la diferencia de fe. Las relaciones en el Vinalopó son mucho más complejas en este sentido. La prioridad de las vinculaciones sociales parece estar más ligada a la pertenencia al señorío feudal, como intento de integración de ambas comunidades bajo el signo del dominio cristiano, que a la pertenencia a un credo religioso concreto ${ }^{11}$.

En este caso, el motivo de la correría de 1457 fue una acción de represalia desde las poblaciones pertenecientes a la familia Corella por el apresamiento de un mudéjar aspense por parte del procurador general de Elche y Crevillente, Francisco Buçot. Este moro había sido detenido a causa de un delito cometido en la villa de Elche. El propio Buçot se encargó de poner en conocimiento del asalto al lloctinent del gobernador de la partida ${ }^{12}$.

El documento no indica el crimen que lleva a Buçot al apresamiento inicial del mudéjar aspense. No sabemos si es un asunto particular o derivado de la con-

10. Los mudéjares permanecieron en tierras señoriales a pesar de los esfuerzos de la monarquía por atraerlos a territorio de realengo. Este deseo era consecuencia en parte de su conciencia islámica, que les impulsaba a conservar su propia cultura y religión, un objetivo más difícil de mantener en el medio urbano, que solía estar altamente cristianizado. La tolerancia hacia otros ritos estaba más diluida y los adeptos y predicadores se mostraban más agresivos contra la fe islámica. Los centros de enseñanza musulmana del Reino se trasladaron a lo largo del siglos XV a las villas señoriales. En estos lugares los mudéjares proporcionaban a sus señores rentas más altas, pero de este modo podían mantener la fe y una comunidad cohesionada. Meyerson, Mark D. «Un reino de contradicciones: Valencia 1391-1526», en Los mudéjares valencianos y peninsulares. Revista d'Historia Medieval. Valencia. No12. 2001-2002, pp.16-17.

11. Los obreros cristianos que protagonizaron los asaltos de 1391, 1455 y 1521 estaban obsesionados por mejorar su status en relación con los demás cristianos, previniéndose de la deshonra personal y familiar. Las autoridades municipales y eclesiásticas, sobre todo los predicadores, insistieron en que su confraternización con las minorías en talleres, hogares, tabernas, burdeles y locales de juego era escandalosa y «atraería sobre la ciudad la ira divina bajo la forma de plagas y carestías». Para Meyerson estos obreros se sintieron marginados por sus contactos con las minorías religiosas, lo que les alejaba de pertenecer a la ciudad cristiana. «Los actos de violencia ritual e institucional contra las minorías... estaban orientados, de algún modo, a calmar temporalmente sus ansias de status, al elevarlos y distanciarles de las minorías» Pero en estos brotes de violencia catártica los agresores no mataban sin más a judíos y musulmanes, sino que les ofrecían la alternativa del bautismo. «Al fin y al cabo, para ellos no se trataba de desconocidos sin rostro, muchos de ellos les eran sobradamente conocidos, a veces clientes, socios de negocios o compañeros de taberna». Meyerson, M. D. «Un reino de contradicciones...», pp. 27-28.

12. Según el documento, el procurador general de Elche y Crevillente tenía preso «vn moro vehi d'azp e li fa proces ordinari per cert delicte per aquell comes en lo terme de la dita villa de Elg, del qual exces contra los dits batles, officials e gent de cauall e de peu, per lo dit procurador de Elg e de Criuillen, es estada posada determinacio e clam deuant lo loch de gouernador de aquella partida». ARV, Real, 279, fol. 209v. 
flictividad existente entre los señores del Vinalopó ${ }^{13}$. Lo que si nos encontramos en la bibliografía es con un caso anterior, que ya supuso un primer enfrentamiento entre el conde de Cocentaina y las ciudades de Elche y Crevillente.

\section{PRECEDENTES. EL CASO DEL ALFAQUÍ.}

María Terresa Ferrer i Mallol aporta información de un suceso previo a esta correría que supuso un enfrentamiento directo entre la ciudad de Elche y los intereses del conde de Cocentaina, un suceso que podría tener algún tipo de vinculación con el asalto relatado.

Ferrer i Mallol sitúa este conflicto anterior en los numerosos enfrentamientos bajomedievales por el control del poder en los municipios valencianos, ya sea entre los cristianos o dentro de las comunidades sarracenas. En Elche, estas luchas llevaron a una disputa directa entre el cadí, Alí Abençanot, y el alfaquí Mahomat Alhaig ${ }^{14}$.

La relación de sucesos se inició cuando el mudéjar Mahomat Alhaig, vecino de la alquería de Almudiana, cerca de Cocentaina, acudió a vivir a Elche en 1432 para ejercer el cargo de alfaquí. En este viaje le acompañaron ocho sarracenos más, que al parecer eran familiares suyos, suegros y cuñados. En Elche se rodeó de un grupo de adeptos con los que se opuso al cadí, Alí Abençanot.

13. La bibliografía aporta numerosa documentación sobre las restricciones que afectaban a los mudéjares valencianos a lo largo de la baja Edad Media y que podrían haber llevado al sarraceno de Aspe a prisión. En algunas ocasiones, estas prohibiciones se aplicaban con gran celo, en otras se apreciaba una mayor permisividad para no fomentar su huida a otros territorios. María Teresa FERRER I MALlol [Els sarraïns de la Corona Catalano-Aragonesa en segle XIV: segregació i discriminació, CSIC, Barcelona, 1987] menciona la prohibición aplicada en 1318 de realizar la llamada de la salà. Se trataba de una disposición papal de obligado cumplimiento para los príncipes cristianos y sus vasallos mudéjares. Entre las aljamas afectadas por esta medida se encontraban las de Elche, Elda, Novelda, Aspe, Chinosa, Monóvar y Orihuela (p.89). En 1366, el batle general dellà Sexona, Joan d'Olit, apresó a una alfaquí y a un almuhaden de Aspe por cantar la salà y llamar a la oración con l'anfil, la trompeta que los sarracenos usaban para este fin. Sin embargo, el rey ordenó que fueran liberados, continuando con una política tendente a tranquilizar a los moros y estimular el repoblamiento de las morerías (p.93). En 1308, el rey Jaime II permitía que los sarracenos compraran y bebieran vino en las tabernas cristianas del raval pero no en la villa. Anteriormente el batle lo había prohibido todo. Pero ocho años más tarde, el propio monarca prohibía que bebieran vino en las tabernas cristianas, porque los sarracenos se emborrachaban, blasfemaban contra el cristianismo y se producían altercados por tal causa (pp.12-13). Junto a estos conflictos sociales y religiosos nos encontramos con otros económicos. En 1311, el consell de la vila de Elche prohibía a los sarracenos vender espardeñas y objetos de esparto en el mercado hasta una determinada hora para que no hicieran competencia a los cristianos. Jaume II pidió al concejo que revocase la medida ya que perjudicaba a los compradores (p.15). En el año 1374, el infante Martín censuraba al justicia y a los jurados de Elche por prohibir sin su consentimiento que los sarracenos hicieran leña, cogieran esparto o sosa en descampado. El infante creía que lo habían prohibido para que los sarracenos vendieran sus tierras a bajo precio al carecer de recursos (p.108).

14. Ferrer i Mallol, M. T., «L'alfaquí Mahomat Alhaig... p.185. 
Mahomat tenía una hija llamada Zoayra que se casó con Muça Almuquetdem, pero este matrimonio se anuló al saberse que el tal Muça estaba lleno de deudas. A continuación Zoayra se casó con Axer Abenzacaria, quien llegó a sustituir Abençanot como cadí ${ }^{15}$.

El choque entre el alfaquí y el cadí se hizo evidente a partir 1448, ya que ambos enviaron mensajeros a Barcelona para ganar el favor de los consellers. Éstos se inclinaron por el cadí y amonestaron al alfaquí ${ }^{16}$. Le ordenaron que sólo se ocupara de asuntos espirituales ya que les había llegado noticia de que después de la salà enardecía a los sarracenos contra los cristianos, pero una encuesta posterior lo desmintió ${ }^{17}$.

Ese mismo año se introdujo en Elche el sistema de insaculación para evitar conflictos en la elección de los cargos. El nuevo sistema no sirvió para cerrar tales luchas ${ }^{18}$. En dicho año, seis miembros del consell aún se mostraban partidarios del cadí, pero en 1449 eran contrarios al mismo, aunque el cadí contaba con el soporte de la ciudad, lo cual no impidió su destitución en 1449. El punto débil del cadí, que aún mantenía el apoyo de los consellers de Barcelona, eran las cuentas de la aljama, lo que fue aprovechado por sus enemigos. Se le acusaba de mala administración, ya que según los vells hacía diez años que se negaba a dar cuentas de su administración. El cadí había acudido cuatro veces a Barcelona para explicar que no estaban

15. Ibidem, p. 188 .

16. «El mudéjar ha sido considerado a menudo como un sector al margen de la sociedad cristiana, sin apenas continuidad con el mundo islámico anterior, al margen de la actividad productiva, política o cultural de los reinos cristianos... La realidad, sin embargo, se muestra mucho más rica y compleja, ya que los mudéjares se insertaron en el sistema político, social, económico y cultural de los estados peninsulares.» HiNOJOSA Montalvo, J., «Los mudéjares en las Coronas de Castilla y Aragón en tiempos del Arcipreste de Hita». Autour du Libro de buen amor. París, 2005, p.73.

17. Ferrer i Mallol, M. T., «L'alfaquí Mahomat Alhaig... p.189.

18. La organización política de la ciudad de Elche desde la conquista de Jaime II contaba con tres pilares fundamentales: un justicia, dos jurados y un Consell, al igual que el resto de municipios del Reino. Los consellers -20 en total- eran elegidos por los dos jurados salientes, los dos vigentes y el justicia. El resto de cargos se elegía por cooptación indirecta a través de unos compromisarios-electores mantenidos por la oligarquía vecinal. El justicia, los jurados y el mostaçaf, junto a los prohombres, nominaban a los electores entre el vecindario y éstos designaban a los nuevos oficiales. A continuación se utilizaba el azar. El justicia era designado por el baile entre los redolines designados anteriormente, mientras que los jurados eran elegidos por azar directo. Este sistema dio lugar a numerosas tensiones, corrupción y nepotismo, junto a la «fosilización del poder local», y no eran extraños los casos de violencia entre los grupos oligárquicos por la obtención del poder. Cabezuelo Pliego, J.V. «La regulación de la elección de los cargos municipales en un espacio señorial: Elx, 1444. Per ço que les dits oficis e repartIsen e’n fosen entre molts bons hòmnes repartits que may ne podien haver e altres n'avien masa sovint», en Acta Historica Et Archeologica Mediaevalia. $\mathrm{N}^{\circ} 26$, Departament d'Historia, Paleografia i Diplomàtica. Institut d'Estudis de la Cultura Medieval. Universidad de Barcelona, 2005, pp. 775-779. A partir de 1447, los munícipes ilicitanos pidieron la alternativa de la insaculación a los consellers de Barcelona. Se solicitó durante un periodo de veinte años, aunque el sistema fue modificado en varias ocasiones a lo largo del siglo XV. Pero este nuevo sistema llevó a las distintas partes a solicitar medidas de discriminación política para mantener el control político. (pp.789-790) 
acabadas y, finalmente, él mismo sugirió una comisión independiente, lo que fue el principio de su propia perdición. La tarea fue encomendada a un vecino de Elche, Andreu Granyana, junto con dos cadíes (uno de Elda y otro de Novelda) y al batle Antoni Balaguer. Antes de que se conociera el dictamen de la comisión, el cadí Alí Abençanot huyó de Elche y se dirigió a la ciudad de Orihuela, intentando avecindarse allí. Los oficiales locales lo aceptaron como vecino pero no se comprometieron a defenderlo contra la justicia. Alí se dirigió a continuación a Barcelona para informar a los consellers de su punto de vista. Una vez hecha pública la resolución, ésta le condenaba a devolver a la aljama de Elche 8.824 sueldos. ${ }^{19}$

Los consellers ordenaron al regente de la procuración y al batle de Elche que suspendieran la ejecución de bienes del cadí hasta que el procurador de la ciudad, que estaban a punto de nombrar, no decidiera otra cosa, y suspendieron a Alí de su cargo de cadí. El regente de la procuración nombró como cadí a Axer Benzacaria o Abenzacaria, yerno del alfaquí Mahomat Alhaig. La derrota de Alí fue total al pasar su cargo a la esfera familiar de su enemigo. Las tensiones y los gastos de los mensajes enviados a Barcelona, el coste de los abogados y de la comisión, provocó el abandono de muchas familias que se trasladaron a localidades cercanas. Cuando Alí regresó por fin a Elche, descubrió que el batle y el alfaquí habían vendido todos sus bienes para compensar la deuda. Incluso la dote de su mujer que según la sunna debía ser preservada. Ante esta situación, Alí pidió justicia a la ciudad de Barcelona. ${ }^{20}$

El 12 de septiembre de 1449, Barcelona nombró a Pere de Relat como procurador de Elche y Crevillente. El nuevo procurador escuchó a las dos partes con la ayuda de varios cadíes. ${ }^{21}$ Tras esta segunda investigación, le descontaron a Alí algunas cantidades de la deuda, pero el ex cadí no pudo presentar documentación exculpatoria del resto. Cuando Alí conoció la sentencia definitiva se preparó para marchar a Orihuela, pero sus fiadores en Elche pidieron al procurador que lo apresara y éste lo hizo en marzo de 1450. A solicitud de la aljama, el procurador ejecutó los bienes de Alí, que sólo sirvieron para pagar un tercio de la condena de 7.825 sueldos, así que ejecutaron también los bienes de sus fiadores. Estos llegaron a un acuerdo y se avecindaron en Elda y en Aspe, propiedad del conde de Cocentaina, Ximén Pérez de Corella. ${ }^{22}$

19. Ferrer i Mallol, M. T., «L'alfaquí Mahomat Alhaig... pp.190-192.

20. Ibídem, pp.193-194.

21. «Los musulmanes aceptaron la condición de vencidos, a cambio de que se les respetara su autonomía religiosa, judicial y comunitaria, sus formas de vida y sus señas de identidad, a cambio del reconocimiento de la soberanía política del poder cristiano y del pago de unos impuestos». Hinojosa Montalvo, J. «Los mudéjares en las Coronas..., p.74.

22. Ferrer i Mallol, M. T., L'alfaquí Mahomat Alhaig... pp.195-196. 
Hasta ese momento, la lucha entre el alfaquí y el cadí era tan sólo un conflicto interno de la aljama de Elche que implicó la intervención de las autoridades cristianas, pero a partir de ahí la situación se complicó al hacer su aparición el conde de Cocentaina, lo que provocó una multiplicación inesperada del problema.

Ximén Pérez de Corella era un noble de linaje poco importante que se distinguió en Italia, enalteciendo así su posición y llegando a ser gobernador de Valencia entre 1429 y 1448 . Cuando los fiadores de Alí decidieron hacerse vecinos de Elda y Aspe, el conde estaba ausente de dichas tierras. Su esposa aceptó a los fiadores como vecinos de Aspe sin preocuparse de los litigios que esto podía abrirle con Barcelona. La acogida de los moros en Aspe fue fatal para los intereses de la ciudad condal al tener que enfrentarse con un señor muy poderoso que tenía detrás suyo al lloctinent del gobernador de Orihuela y al batle general, que le seguían fielmente. Los representantes de Orihuela y la condesa solicitaron la revisión del proceso porque, en su opinión, los jueces habían estado bajo la influencia de una de las partes. La condesa amenazó con represalias si los fiadores eran perjudicados. Además, el ex cadí logró fugarse de Elche y se refugió en Aspe, donde fue acogido por la condesa. No contenta con acogerlos, la esposa de Ximén autorizó actos de represalia contra los vasallos de Elche. El 28 de agosto de 1450, seis cristianos y dos moros ilicitanos fueron presos en los términos de Elda y Novelda. El 7 de septiembre Arnau Rosell y Domingo Civera procuradores de conde se hicieron acompañar por catorce hombres a caballo y cien a pie, y capturaron a tres moros en el término de Elche, llevándolos presos. Pere de Relat persiguió a los invasores hasta Aspe. Para no empeorar las cosas decidió no entrar en el lugar. Los seguidores del conde interpretaron esta decisión como una muestra de debilidad y al día siguiente Arnau Rosell y su gente realizaron una nueva incursión en la huerta de Elche capturando a ocho moros con sus bestias y llevándolos a Aspe. El lloctinent de la gouernació de Orihuela sólo se preocupó de que Elche no tomase represalias contra las propiedades del conde de Cocentaina ${ }^{23}$.

Ante esta situación, los consellers de Barcelona solicitaron la intermediación del rey de Navarra, Juan II, lloctinent general del rey Alfonso en el Reino de Valencia y en Aragón. A partir de aquí se inicia un cruce de cartas y declaraciones justificativas de una y otra parte. La posición de Barcelona era difícil ya que tenían que defender sus intereses pero no querían enfrentarse al conde de Cocentaina, personaje muy influyente cerca del rey Alfonso. Los enviados de Barcelona comunicaron la situación al propio conde antes que al rey. Ambos se encontraban en Nápoles, y el conde les prometió enmendar los perjuicios ocasionados. A continuación escribió a su hijo Joan censurando el enfrentamiento.

23. Ibidem, pp.197-198. 
Éste aceptó el arbitraje del rey Alfonso o del rey de Navarra. Juan II inhibió al lloctinent del gobernador de Orihuela, Jaume Rocamora, y nombró juez a Pere Cabanyelles, lloctinent del gobernador en Valencia. Mientras tanto, Joan de Corella liberó a los cristianos apresados, pero mantuvo a los moros. El lloctinent del gobernador los llevó presos a Orihuela. Algunos murieron en prisión y otros cayeron enfermos. Por su parte, Pere Cabanyelles ordenó su liberación, pero Jaume Rocamora sólo los liberó después de una consulta con el rey de Navarra el 7 de marzo de 1451. Para debilitar el conflicto, el procurador de Elche cedió ligeramente en la ejecución de los bienes muebles de los fiadores del ex cadí, pero mantuvo la prohibición para que no pudieran regresar a Elche. Por su parte, los moros que habían sido hechos prisioneros demandaron que se les devolvieran los bienes más una indemnización. Pero la causa contra el conde de Cocentaina quedó sobreseída, lo que provocó un gran disgusto en la aljama de Elche ${ }^{24}$.

Poco después, la ciudad se plegó a las exigencias del conde y destituyó al batle Antoni Balaguer, a quien la gente del conde echaba las culpas del incidente. Pero en abril de 1452 el cadí, los vells, las aljamas y el pueblo de Elche y Crevillente lograron la restitución en el cargo de Antoni Balaguer ${ }^{25}$. El conflicto no había terminado ya que se mantuvo con algunos pequeños incidentes. Uno de ellos se produjo cuando Joan de Corella envió a Amet Bençot, uno de los fiadores del ex cadí, con una carta a Elche. Amet pidió que le dejasen vender sus bienes, pero al no permitírselo se enfrentó con el abogado fiscal Pere Granyana. El procurador lo detuvo durante un día. Joan de Corella se indignó porque habían hecho preso a su enviado y encarceló como represalia al alfaquí de Elche, Mahomat Alaihg, que casualmente estaba en Aspe, dejándolo marchar sólo cuando Amet fue liberado. La condesa y su hijo afirmaban que la reconciliación sólo llegaría cuando se abolieran todos las procesos pendientes contra los fiadores. Pero el procurador de Elche no quería ceder a los imposiciones de los Corella. En enero de 1452 se produjo una reunión en Aspe. Pere de Relat, con otros miembros de la morería, visitaron al conde de Cocentaina para solucionar los problemas pendientes. El conde pidió que sus vasallos pudieran entrar en Elche con total libertad. El

24. Ibidem, pp.199-201.

25. Frente a las etiquetas musulmán, judío o cristiano, Brian A. Catlos expone que en la Corona de Aragón «la identidad de un musulmán como tal podía haber sido bastante menos relevante que otros factores como el género o el papel desempeñado en las relaciones económicas (titular de una tenencia, terrateniente, trabajador, deudor) para determinar su percepción o la línea de conducta que podía tomar.» Esta idea es aplicable a un acontecimiento en el que aparecen otros intereses por encima de un sectarismo meramente religioso. Así se pone de manifiesto que «cristianos, musulmanes y judíos se mezclaban unos con otros en un conjunto de esferas: en la tributación, como tenentes y dueños de tierras, acreedores y deudores, productores y consumidores, administradores y subordinados...» CATLOS, B. A., «Contexto y convivencia en la corona de Aragón: propuesta de un modelo de iteracción entre grupos etno-religiosos minoritarios y mayoritarios». Los mudéjares valencianos y peninsulares..., p.261. 
procurador accedió a esa petición pero no a anular los procesos contra los que habían entrado en el término de Elche en la correría. Aún así dejó el asunto en manos de los consellers de Barcelona. El conde pidió información sobre el proceso entre la aljama y el ex cadí, y aseguró que algunas cantidades de la deuda estaban cargadas injustamente, por lo que demandó que se volviera a hacer justicia. El procurador cedió ante esta solicitud ${ }^{26}$.

A pesar de tales acuerdos, el hijo del conde aportó nuevas exigencias, que Pere no pudo aceptar. La defensa del cadi y de sus fiadores por parte del conde no era altruista, ya que habían firmado un escrito por el que no se podían desvasallar durante veinte años. Por si el asunto no estaba suficientemente enredado, el primer yerno del alfaquí, Muça Almuquetdem, se refugió en las tierras del conde. Desde allí pidió la restitución de su esposa y acciones contra el alfaquí de unos bienes que tenía en Aspe (joyas y telas de seda). El batle de Aspe secuestró dichos bienes y el alfaquí demandó su devolución, pero ni él ni el batle de Elche, Antoni Balaguer, lo consiguieron. La historia de las joyas continuó hasta 1454. Todos estos conflictos hicieron que los vecinos de Elche solicitaran al rey un juez especial, pero el juez de Orihuela se encontraba ausente y su lloctinent, Jaume Rocamora, era demasiado parcial a favor del conde ${ }^{27}$.

En un paso que demuestra gran decisión, Rocamora envió un porter y un notario a Elche para prender al alfaquí ante las reclamaciones del anterior yerno y se presentaron en su casa para ejecutar la orden. El lloctinent del procurador y el batle acuden a la morería a tiempo para evitar la detención. Los oficiales de la gobernación tuvieron que volverse de vacío pero el lloctinent del gobernador y el batle general iniciaron un proceso contra los oficiales de Barcelona por resistencia a la autoridad y amenazaron con hacerse con la posesión de la jurisdicción de la ciudad. Los oficiales de Barcelona, el cadí y los vells de la morería pidieron protección a los consellers. Jaume Rocamora y el batlle general se reunieron con el conde en Aspe y decidieron acudir a Elche para apresar los oficiales de Barcelona que habían impedido la detención del alfaquí. El plan fue abortado por Lluís Cornell, gobernador del Reino de Valencia, que se encontraba en Novelda y se dirigía a Elche. El lloctinent del gobernador y el batlle general abandonaron la incursión y acudieron a Elche con las denuncias presentadas. El gobernador se negó a prender a los oficiales pero los arrestó. Tras este suceso se produjo un nuevo intercambio de cartas ante el rey por parte de los consellers de Barcelona y del conde para exponer cada uno sus puntos de vista ${ }^{28}$.

26. Ferrer i Mallol, M. T. «L'alfaquí Mahomat Alhaig... pp.202-205.

27. Ibidem, pp.206-208.

28. Ibidem, pp.210-211. 
A partir de 1453, el rey de Navarra empezó a despachar algunas provisiones sobre el asunto, lo cual fue del agrado del cadí y de los vells de Elche, pero no abandonaron sus protestas ya que los hombres del conde retenían en Aspe a cuatro mulos de los moros de Crevillente.

Toda esta situación se había iniciado con las disputas entre el alfaquí y el ex cadí dentro de la lucha interna de la aljama de Elche ${ }^{29}$. En 1449 había triunfado la facción del alfaquí pero esta victoria no duró demasiado. Los moros de Crevillente pidieron la revocación del nuevo cadi, el segundo yerno del alfaquí, en 1453. Las autoridades de la aljama culpaban de las críticas contra el yerno a Çaat Sarriá, próximo al ex cadín ${ }^{30}$.

Como consecuencia de estas disputas Mahomat Alhaig resultó destituido de su cargo de alfaquí por los miembros de la aljama en el verano de 1453. Los vells denunciaron ante el nuevo regente de la procuración, Joan Ferràndez de Mesa, que Mahomat había organizado una salà alternativa en el campo con su yerno (el cadí) y su hijo al finalizar el Ramadán, algo que estaba prohibido por la sunna y la xara. Las autoridades cristianas intervinieron ante esta salà alternativa y llevaron preso a Mahomat, pero éste afirmó que tenía licencia de Pere de Relat, lloctinent general i portanveus de senyor, y lo liberan.

Como se puede comprobar, en este caso hay gran variedad de intereses, sucesos y ramificaciones que se entrecruzan y se confunden los unos con los otros. Así, entre 1453 y 1454 se produjeron diversas negociaciones entre el conde y Pere de Relat Poco después, un gran tribunal, compuesto por el batle Antoni Balaguer y un gran consell de cadíes y alfaquíes del Reino de Valencia y Granada decide que Zoayra, era la mujer del primer marido, que se había hecho vasallo del conde en Aspe ${ }^{31}$. Ante esta decisión, Zoayra es trasladada a Monforte, territorio neutral. Inesperadamente, su padre se había hecho vasallo del conde para obtener su favor, algo que sorprendió a muchos ya que Ximén era el protector de los fiadores de su gran enemigo, el ex cadí. Su hija finalmente no se encontró con el primer marido, sino que en 1456 fue llevada a Italia con un hijo del segundo marido. La familia del alfaquí se trasladó a Aspe, ya que se habían convertido

29. «Las fuentes documentales destacan el alto grado de violencia existente en la sociedad mudéjar, consecuencia de la solidaridad agnaticia. Cualquier agresión era vengada por los hijos, hermanos, tíos o primos el agredido. El odio de sangre entre familias y linajes tenía como base la riqueza y el poder, el control por la tierra, por el mercado o por el control del poder político de la aljama.» Hinojosa MonTALvo, J. «Los mudéjares en las Coronas..., p.79.

30. Ferrer i Mallol, M. T., «L'alfaquí Mahomat Alhaig..., p.213

31. Según manifiesta Hinojosa Montalvo, en la sociedad mudéjar no se puede hablar de una marcada jerarquización social, pero sí que en las aljamas más importantes existía un grupo de acomodados que controlaban los cargos públicos perpetuándose en ellos. De este modo sí se puede hablar de una elite religiosa o económica. Hinojosa Montalvo, J., «Los mudéjares en las Coronas..., p.77. 
en vasallos del conde, pero él quedó en Elche, arrepentido de haberse hecho vasallo de Ximén y pidiendo el amparo de Barcelona. Los consellers siguieron considerándolo vasallo suyo, pero estaban cansados de los conflictos que había originado y de que se hiciera vasallo del conde mientras ellos lo defendían con fuerza. Además, había sembrado la disensión en la morería por lo que muchos de sus habitantes se habían fugado. A pesar de las críticas de los oficiales de Barcelona en Elche, los consellers siguieron defendiendo al alfaquíi ${ }^{32}$.

Mientas su familia estaba presa en el castillo de Elda, en junio de 1455 el juez de la causa dictaminó que la mujer y la hija del alfaquí eran vasallos del conde, y que éste las podía detener y juzgar. A pesar de la apelación de los abogados de la ciudad, el conde se llevó a la familia de Mahomat hasta Nápoles. Pero un terremoto asoló Italia en 1457 y murieron la mujer de Mahomat y el hijo de Zoayra. Ésta y otro hijo del alfaquí resultaron heridos. Cuando el conde muere en 1458, el rey decide que el alfaquí y su familia deben volver a Cataluña para ser juzgados por el gobernador. Ferrer i Mallol supone que al final todos pudieron regresar a Elche. Para completar este panorama podría decirse que desde el año 1454, el cadí Abenzacaria, yerno de Mahomat, había recogido numerosas críticas. Las elecciones de junio fueron accidentadas y resultaron desfavorables para el cadí, que presentó un recurso para anularlas. Los oficiales cristianos intervinieron en la elección. La aljama protestó porque esto nunca se había producido antes. Para evitar una lucha armada, el batle escogió a los vells entre los nombres que habían tenido más votos. Todas estas disensiones en la aljama coincidieron con un periodo económico difícil que se inició en 1448 por una gran sequía. Algunos vecinos se trasladaron a Orihuela, Albatera o La Daya. El cadí Axer Abenzacaria fue cesado posiblemente en 1458 y se nombró a otro cadí. Se le abrió proceso y se comprobó que había hecho numerosos fraudes, fue arrestado, pero huyó. Joan Ferràndez de Mesa fue destituido como procurador ante las peticiones del conde de Cocentaina y del alfaquí, del justicia y los jurats, y por las luchas de bandos existentes en Elche. Se nombró a un barcelonés, Francisco Busot, el 14 de diciembre de $1456 .{ }^{33}$ Como ya hemos visto con anterioridad, Busot fue uno de los personajes destacados en el caso del asalto a Crevillente en junio de 1457.

\section{OTRAS REFERENCIAS Y CONFLICTOS}

Ferrer i Mallol no es el único investigador que ha estudiado el caso del alfaquí y del cadí. En su obra, La morería de Elche en la Edad Media, Hinojosa

32. Ferrer i Mallol, M. T., «L'alfaquí Mahomat Alhaig... pp.216-226.

33. Ibidem, pp.226-239. 
Montalvo también hace referencia a este asunto. Según indica el profesor Hinojosa, en el año 1456 el alfaquí, Mahomat Alhag, se encontraba preso en la cárcel de Elche a instancias del conde contestano, de quien había sido vasallo.

El pleito databa de 1454. En junio de dicho año, los consellers de Barcelona habían pedido al procurador y batle de Elche que defendiera a Mahomat ante todas las causas civiles y criminales que tuviera con el conde. Pero los jurados ilicitanos manifestaron su queja ante las autoridades de Barcelona ya que el procurador no había defendido al alfaquí, sino que lo mantenía encerrado.

La causa de las diferencias entre el mudéjar y el conde hay que buscarla en el hecho de que el alfaquí se había marchado de Cocentaina a Elche sin pagar ni cancelar los derechos que debía a su señor, más de 300 florines de pena, ya que se había comprometido a ser vasallo del conde durante cinco años y no lo había cumplido.

Además, existían ciertas reclamaciones contra el alfaquí por parte de algunos mudéjares vasallos del conde, deseando el señor ejecutar los correspondientes embargos contra Mahomat.

El procurador de Elche actuó con cierta precipitación a la hora de encarcelar al alfaquí, ya que no esperó el dictamen jurídico de Francesc de Vilafranca, abogado de Orihuela, al que los jurados de Elche pidieron su opinión sobre el citado conflicto. Posteriormente, los jurados intentaron sacarlo de prisión, depositando las fianzas correspondientes, pero el procurador se negó a liberarlo, alegando que debía consultarlo con Valencia. Los jurados elevaron a Barcelona su protesta ya que tal medida iba en contra de los fueros de la villa, puesto que nadie podía estar en prisión si depositaba las fianzas salvo los condenados a muerte, por lo que pedían la libertad del mudéjar. ${ }^{34}$

Pero éste no es el único pleito entre el conde de Cocentaina y sus vasallos emigrados a Elche. El 2 de octubre del año 1455, Juan II de Navarra, lloctinent del Reino ordenó a Jaume Masquefa de Orihuela que se encargara de una apelación con la ayuda del abogado Miquel Dalmau. La causa era entre el procurador y batle de Elche y Crevillente, en nombre de la ciudad de Barcelona, y el conde de Cocentaina. En el centro de la apelación se encontraba un alfaquí de la morería de Elche, Uxorem Alcayni. No se indica el motivo del pleito, pero podría ser una reclamación de impuestos atrasados por parte del señor de Cocentaina ${ }^{35}$.

Según Hinojosa Montalvo, los musulmanes que abandonaban su señorío eran normalmente los que poseían mayores recursos económicos, porque eran los que podían pagar las deudas y las obligaciones impuestas por el señor. Además, estos

34. Hinojosa Montalvo, J. La morería de Elche ..., p. 38-39
35. Ibídem. 
vasallos mantenían los derechos sobre las tierras que poseían, así que los señores trataron de obstaculizar en la medida de lo posible esta marcha ${ }^{36}$.

En medio de esta complicadísima situación se produjo el encarcelamiento del mudéjar aspense, y la correría contra Crevillente que supuso la muerte de un moro crevillentino y la captura de otros seis por parte de los vasallos de Alfonso Ximén Pérez de Corella.

La vinculación de este asalto al caso del alfaquí nos es desconocida, ya que no se explica el motivo del encarcelamiento del mudéjar aspense, pero lo cierto es que desde los partidarios del conde se había iniciado una dinámica de bandolerías y correrías armadas contra Elche y Crevillente cuando la rivalidad entre ambos señoríos se incrementaba. Estos actos de represalia o castigo eran una muestra de la conflictividad existente y de cierta impunidad a favor de los intereses del conde ${ }^{37}$.

\section{CONFLICTO JURISDICCIONAL}

Regresando al asalto de 1457, nos encontramos ante un hecho armado ocurrido entre pobladores dependientes de dos señoríos distintos, cuya resolución hizo

36. Hinojosa Montalvo, J., Los mudéjares. La voz del Islam en la España cristiana, Instituto de Estudios Turolenses, Centro de Estudios Mudéjares, Teruel, 2002, p.72.

37. Los pleitos entre la aljama de Aspe y el concejo de Elche fueron numerosos no sólo por las relaciones entre los señores feudales sino también por un asunto tan espinoso como el de los aprovechamientos hídráulicos del río. Estos pleitos se iniciaron cuando el infante Don Manuel, Adelantado de Reino de Murcia, concedió el 20 de junio de 1269 mediante privilegio que todas las aguas del Vinalopó pasasen a propiedad de concejo ilicitano. Aspe jamás admitió las restricciones impuestas en la explotación de cauce de este río ni de su afluente, el Tarafa, y Elche defendió sus derechos confirmados posteriormente por el monarca aragonés Jaime II y por sus sucesores. Hay documentados numerosos conflictos entre vecinos de Aspe y de Elche por las aguas del Tarafa, con acciones jurídicas constantes y graves alteraciones de lo que ahora llamaríamos orden público. Ante el freno al desarrollo agrícola que suponían estas restricciones, Aspe apeló a la Real Audiencia de Valencia que emitió una sentencia a favor de los derechos de Elche el 21 de abril de 1459. De este modo, la señoría de Aspe no pudo contar entre sus rentas con la venta de agua ni con la explotación de molino alguno sobre el Tarafa. Esta situación cambió cuando Aspe pasó a manos de la familia Cárdenas en 1497, señores por aquel entonces de la ciudad de Elche. [VV. AA. Aspe, medio fisico..., pp.203-204] Estas limitaciones no afectaron únicamente al alodio de Aspe. GonZÁlez i Hernández [Musulmans...] indica que desde 1422 se conocen obras para represar el río Vinalopó en Elda, Monforte y Aspe, hechos que el concejo de Elche puso en conocimiento del gobernador de Orihuela. Su reclamación se basaba en los antiguos privilegios concedidos por el infante Don Manuel en 1269. En 1480 el rey Fernando II confirmaba esos privilegios a Elche, avisando al señor de Novelda sobre la imposibilidad de tener más agua que la que ya extraían sus vasallos (p. 110). Según la documentación, la aljama de Aspe se abastecía de tres fuentes dentro de la rambla del Tarafa con dos balsas de almacenamiento y distribución de acequias en los parajes del Fauquí y el Aljau. Entre los pleitos con Elche por el asunto de agua destaca el año 1452, cuando el conde de Cocentaina mandó construir un molino torrenter en la falda de Aspe el viejo, cerca de la confluencia entre el Vinlopó y el Tarafa. Elche protestó a través de su abogado en Valencia porque perjudicaba sus antiguos derechos. Aspe recibió el apoyo de Monforte, interesado en restringir los derechos de Elche. El conde de Cocentaina ganó el pleito y construyó el molino en 1453. A partir de ese momento Elche presentó varios recursos hasta que intervino el rey Juan II. El monarca ordenó que el conde destruyera la rafa o azud del río. La sentencia se cumplió en 1459 (p. 112). 
necesaria la intervención real. El texto que nos sirve de base es precisamente la respuesta del rey Juan II de Navarra a estos acontecimientos, ordenando al batle dellà Sexona, Jaume Roca ${ }^{38}$, que intervenga en el asunto, pues hasta el momento no había mostrado demasiado interés por los acontecimientos.

El documento explica que Francisco Buçot, procurador general de Elche y Crevillente, se dirigió al lloctinent del gobernador de la partida nada más conocer el asalto. Éste se inhibió al no comprender las causas tocantes al conde de Cocentaina. El propio lloctinent remitió el hecho a Jaume Roca, que era el juez impuesto al conde por el monarca ${ }^{39}$. Pero al poner en conocimiento del hecho ante Roca, éste hizo una simple provisión y mandó citar los delitos sin apresar a los delincuentes ni recuperar las personas ni los materiales requisados en la correría. Ante la incomparecencia a las citaciones, Jaume Roca no prosiguió con el trámite afirmando que no le atañía ${ }^{40}$.

¿Se trata de un caso de desinterés por parte de Jaume Roca? ¿O de una muestra de apoyo del batle al conde de Cocentaina? El documento no lo aclara, pero sí expresa la protesta de Francisco Buçot para quien la actitud de Roca es un mal ejemplo contra la justicia y los fueros, además de acusar a Roca de hacer un gran favor al conde, sus oficiales y vasallos, en contra de la justicia y de la ciudad de Barcelona, señoría de dichas villas. Seguidamente califica de peligroso juzgar el caso ante un juez tan sospechoso y solicita al rey que no permita tal situación ${ }^{41}$.

El punto de vista que aparece en el documento es el de Francisco Buçot. El monarca expone sus argumentos para imponer a Roca una mayor implicación a la hora de resolver los hechos. Además, la impunidad de tal correría habría permitido su repetición, ya que el batle de Elda, no contento con el primer delito,

38. Ferrer i Mallol menciona a Jaume Rocamora como lloctinent del gobernador de Orihuela. En el documento de 1457 se habla de Jaume Roca o Jaume Rocha, que según indica Juan Antonio Barrio era el baile general dellà Sexona en 1456. BArrio BARrio, J. A., Gobierno municipal en Orihuela durante el reinado de Alfonso V, 1416-1458. Universidad de Alicante, 1995, p. 237.

39. Estamos por tanto ante una bandolería nobiliaria con implicaciones jurisdiccionales que hace plantearnos también cuál es la situación jurídica del reino. En este sentido la bibliografía apunta una posible respuesta: el poder de las familias señoriales que dominaron las tierras y comarcas del Vinalopó se reflejaba en el nombramiento de los gobernadores de la gobernación de Orihuela durante el siglo XV. Entre 1428 y 1479 los Maça de Liçana (señores de Novelda y enemigos del conde de Cocentaina) residieron en Orihuela. En 1428 fue nombrado gobernador Pere Maça de Liçana, el major; en 1451 fue Lluis Cornell y en 1479 finalizaba su mandato otro Pere Maça. [GonzÁlez i Hernández, M. À. Musulmans..., p. 46] Así que, durante buena parte del siglo XV coincidieron en el medio Vinalopó dos familias que rivalizaron en influencia política ante el rey de Aragón, los Corella y los Maça de Liçana. Joan Roíç de Corella (hijo de Ximén) fue lloctinent general del reino de Valencia. Alfonso V dio a los Corella un privilegio real para que no dependieran jurídicamente de los Maça aunque residieran en la gobernación de Orihuela (p. 47)

40. ARV, Real, 279, fol. 280.

41. ARV, Real, 279, fol. 280. 
regresó al término de Elche con doce caballos y veinticinco peones rompiendo el camino real, asaltando y haciendo prisioneros a cinco cristianos y tres moros de Elche y de Crevillente, con tres bestias cargadas de alfombras y una de harina, llevándolo todo al lugar de Elda. A pesar de este crimen, indica Buçot, Jaume Roca no quiso hacer justicia ante lo sucedido ${ }^{42}$.

Como solución a este conflicto, Buçot proponía un juez imparcial, un hombre notable de la ciudad de Orihuela que no fuera sospechoso de parcialidad ${ }^{43}$. Éste debía realizar la provisión de los hechos hasta su definitiva solución junto al escribano y al consejo ordinario del gobernador de la partida, mandándole expresamente que detuviera a los «malhechores» y que recuperaran los hombres y cosas apresadas en el asalto. La aparente parcialidad de Roca en favor de la familia Corella impulsaba al procurador general de Elche a realizar esta solicitud.

\section{SOLUCIÓN INTERMEDIA}

Ante la súplica de Buçot, Juan II resolvió una solución intermedia, que no era la de pasar por encima del batle general, como solicitaba Buçot, ni la de dar por válida la decisión de juez. En cambio, la decisión del monarca fue recordar a Roca que a él le competía cualquier causa civil o criminal en el territorio que componía su jurisdicción. Con el consejo de Francisco Vilafranca, lloctinent y asesor ordinario de la gobernación a la que pertenecía la partida, le ordenaba que tomase al propio Vilafranca como asesor accidental para esta o cualquier otra causa, con el objetivo de que se hiciera justicia. También le indicaba que recuperase a los moros y demás bienes robados, admitiendo las contumacias denunciadas «según fuero, justicia y buena razón». Además, le imponía una multa de 10.000 florines de oro en caso de contravenir la orden. La decisión del rey era por tanto que se hiciera un «juicio breument, sumaria, simple e de pla, sens strepitu e figura de iuhi atsesa la veritat $\rangle^{44}$.

Nada más se conoce de lo acontecido. El documento, dirigido a Jaume Roca, expresa la necesidad de resolver el caso y las directrices necesarias para juzgar los hechos, pero evidentemente no incluye el resultado final. Aún así, el texto nos sirve para comprender cómo una bandolería nobiliaria protagonizada por los vasallos de un señor del Medio Vinalopó, desemboca en un conflicto de competencias jurisdiccionales, en el que se ven implicados los máximos poderes del Reino de Valencia.

\footnotetext{
42. ARV, Real, 279, fol. 280.

43. No hay que olvidar que Orihuela ostentaba la capitalidad de la gobernación ya que allí residía habitualmente el procurador. FerRer i MaLlol, M.T., Les aljames sarraines..., p.6.

44. ARV, Real, 279, fol. 280v.
} 